\title{
THE INTERACTION OF HYDROGEN AND CARBON MONOXIDE WITH OXYGEN ON Cu(110)-Fe SURFACES
}

\author{
O.P. VAN PRUISSEN, O.L.J. GIJZEMAN and J.W. GEUS \\ Van 't Hoff Laboratory, University of Utrecht, Padualaan 8, $3584 \mathrm{CH}$ Utrecht, The Netherlands
}

Received 9 April 1987; accepted for publication 6 July 1987

The interaction of hydrogen and carbon monoxide with oxygen adsorbed on $\mathrm{Cu}(110)-\mathrm{Fe}$ surfaces has been studied with ellipsometry, Auger electron spectroscopy and low energy electron diffraction. With carbon monoxide copper can be reduced completely and $\mathrm{Fe}_{0.95} \mathrm{O}$ partially. With a model which is only an extension of the scheme for the reduction of pure $\mathrm{Cu}(110)$ by $\mathrm{CO}$, the reduction of $\mathrm{Cu}(110)-\mathrm{Fe}$ can be simulated. The lateral orientation of $\mathrm{Fe}_{0.95} \mathrm{O}$ with respect to the copper matrix changes during repetitive oxidation-reduction cycles. At $725 \mathrm{~K}$ oxygen deficient iron oxide segregates to the surface. With hydrogen all oxygen can be removed.

\section{Introduction}

In this paper investigations on the reaction of carbon monoxide and hydrogen with oxygen adsorbed on $\mathrm{Cu}(110)-\mathrm{Fe}$ surfaces are described. The surface alloys are prepared by thermal decomposition of iron carbonyl onto a clean $\mathrm{Cu}(110)$ surface [1].

Carbon monoxide reacts readily with oxygen adsorbed on copper surfaces even when it is alloyed with iron. On $\mathrm{Cu}(111)-\mathrm{Fe}$ it was observed that $\mathrm{CO}$ did not react with iron oxide (except in the case of $\gamma-\mathrm{Fe}_{2} \mathrm{O}_{3}$ ). This parallels the behaviour on pure iron [3], but oxygen adsorbed on bare copper could be removed easily.

The dependence of the reaction rate of hydrogen with oxygen on the hydrogen pressure is $p^{1.0}$ for pure $\mathrm{Cu}(111)$ but changes to $p^{0.5}$ when $\mathrm{Cu}(111)$ is alloyed with iron [2] even at small amounts of iron [4]. The reaction rate of the main reduction stage was proportional to the amount of iron deposited.

The purpose of this study is to investigate whether $\mathrm{Cu}(110)-\mathrm{Fe}$ has the same properties as $\mathrm{Cu}(111)-\mathrm{Fe}$ or, if other features are observed, try to explain the differences in terms of geometrical arguments.

\section{Experimental}

For the technical data, the crystal preparation and the calculation of the iron mole fraction we refer to refs. $[1,5,6]$. To determine a possible stoichiome- 
try of iron the peak ratio $h_{\mathrm{O}} / h_{\mathrm{Fe}}$, where $h_{\mathrm{O}}=h_{515}$ is the peak to peak height of the oxygen AES $515 \mathrm{eV}$ signal and $h_{\mathrm{Fe}}=h_{651}$, was monitored during sputtering. Since copper could be reduced completely by $\mathrm{CO}$, a constant peak ratio indicates a constant oxygen to iron ratio. The surface was sputtered with $\mathrm{Ar}^{+}$ions of $450 \mathrm{eV}$ at a current of $500 \mathrm{nA} \mathrm{cm}^{-2}$. Based on the measurements performed on $\mathrm{Cu}(111)-\mathrm{Fe}$ during $1000 \mathrm{~s}$ sputtering 6 atomic layers will be removed.

The interaction of $\mathrm{H}_{2}$ or $\mathrm{CO}$ with oxidized $\mathrm{Cu}(110)-\mathrm{Fe}$ alloys was monitored continuously with ellipsometry. Since after oxidation no facets of iron are present [6] the parameter $\delta \Delta$ can be taken directly proportional to the amount of oxygen. The absolute coverage of oxygen $\theta_{\mathrm{O}}$ is based on the occurrence of a $(2 \times 1)$ LEED pattern on $\mathrm{Cu}(110)$ which is equivalent to $\theta_{\mathrm{O}}=0.5[4,7]$.

\section{Results}

\subsection{Interaction with $\mathrm{CO}$}

The reaction of $\mathrm{CO}$ with fully oxidized $\mathrm{Cu}(110)-\mathrm{Fe}$ surface alloys containing different amounts of iron is studied at pressures from $10^{-3}$ to $10^{-1} \mathrm{~Pa}$ and crystal temperatures of $475-750 \mathrm{~K}$. The oxidation of a $\mathrm{Cu}(110)-\mathrm{Fe}$ crystal was carried out in three or four steps. First the crystal was exposed to oxygen at $425 \mathrm{~K}$ until (almost) saturation occurred and subsequently the routine was repeated at 550 and $675 \mathrm{~K}$; if $\mathrm{CO}$ was exposed above $675 \mathrm{~K}$ another oxygen exposure at $775 \mathrm{~K}$ was performed. When no such proper pretreatment was given relatively low reaction rates were measured especially at high temperatures and no straight Arrhenius plot was found. The experiments could only be performed at one iron mole fraction: $x_{\mathrm{H}}(\mathrm{Fe})=0.20$ due to surface segregation effects [6].

As for $\mathrm{Cu}(111)-\mathrm{Fe}$ it is impossible to remove all oxygen from the surface with $\mathrm{CO}$ in the pressure and temperature range studied. After $\mathrm{CO}$ exposures Auger spectra showed no carbon peak. The reaction rate is proportional to the $\mathrm{CO}$ pressure. At temperatures below $550 \mathrm{~K}$ the mole fraction of iron in the surface region, $x_{\mathrm{H}}(\mathrm{Fe})=0.20$ does not change during $\mathrm{CO}$ exposure. At temperatures of $650-750 \mathrm{~K} x_{\mathrm{H}}(\mathrm{Fe})$ increases to $0.28 \pm 0.02$; at $550-650 \mathrm{~K}$ intermediate mole fractions are observed.

A significant difference in kinetics of oxygen removal and LEED patterns between the first $\mathrm{CO}$ exposure and those after the third $\mathrm{CO}$ exposure was observed. Therefore a distinction between those two reaction types is made.

\subsubsection{First admittance of $\mathrm{CO}$}

Fig. 1 shows $\delta \Delta$ as a function of the $C O$ exposure at different temperatures. First the reaction rate is slow, but then it abruptly increases and next falls 


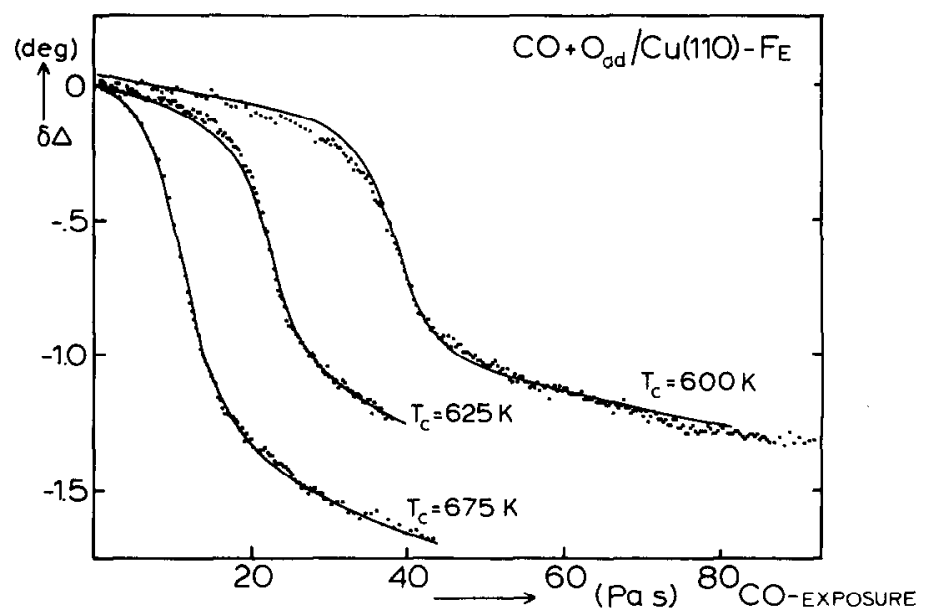

Fig. 1. $\delta \Delta$ versus first $\mathrm{CO}$-exposure to fully oxidized $\mathrm{Cu}(110)-\mathrm{Fe}$ surface alloys at $x_{\mathrm{H}}(\mathrm{Fe})=0.20$ and different temperatures. Solid lines denote solution of eqs. (2)-(5), (7) and (8). $\delta \Delta=0.5$ corresponds to $\theta_{\mathrm{O}}=0.5$.

gradually to zero. The first two stages are also observed on pure $\mathrm{Cu}(110)$ [4], although the second involves only a change of $0.4^{\circ}$ in $\delta \Delta$ there. So the total amount of oxygen which can be removed by $\mathrm{CO}$ is much larger than for pure $\mathrm{Cu}(110)$. The reaction probability of the fast reduction stage, defined as the number of oxygen atoms removed per incident $\mathrm{CO}$ molecule, was calculated as a function of $1 / T$ and is shown in fig. 2. The reaction rate on $\mathrm{Cu}(110)-\mathrm{Fe}$ is 0.75 times the one on $\mathrm{Cu}(110)$. The apparent activation energies for $\mathrm{Cu}(110)-\mathrm{Fe}$ and pure $\mathrm{Cu}(110)$ which can be deduced from this Arrhenius plot are equal within experimental error and are determined to be $E_{\mathrm{act}}=31.5 \pm 0.5 \mathrm{~kJ} / \mathrm{mol}$. Habraken and Bootsma [7] have measured $E_{\text {act }}=27 \pm 2 \mathrm{~kJ} / \mathrm{mol}$ for pure $\mathrm{Cu}(110)$ and an absolute reaction rate which is a factor 1.3 larger. The linear stage before the inflection point is analysed analogously. Above $550 \mathrm{~K}$ the apparent activation energy is $E_{\text {act }}=31 \pm 3 \mathrm{~kJ} / \mathrm{mol}$, the absolute reaction rate depends on the temperature at which the final oxidation was performed and on the amount of iron deposited.

The AES peak ratio after prolonged reduction, only performed at temperatures above $650 \mathrm{~K}$, was $h_{\mathrm{O}} / h_{\mathrm{Fe}}=3.45 \pm 0.10$ and next to the 44 and $51 \mathrm{eV}$ peaks a $47 \mathrm{eV}$ peak was observed. When the reduction was interrupted at 575 $\mathrm{K}$ after the fast reduction stage $h_{\mathrm{o}} / h_{\mathrm{Fe}}=3.9 \pm 0.2$ was measured and no 47 $\mathrm{eV}$ peak was observed. After reduction the crystal was sometimes sputtered. Fig. 3a shows a sputter profile after reduction at $575 \mathrm{~K}$ interrupted after the fast stage, fig. $3 \mathrm{~b}$ shows the corresponding peak ratio $h_{\mathrm{O}} / h_{\mathrm{Fe}}$ as a function of sputter time. There is an enrichment of iron(-oxide) in the outer layers, but there is also more iron in deeper layers than after deposition of iron; when a 


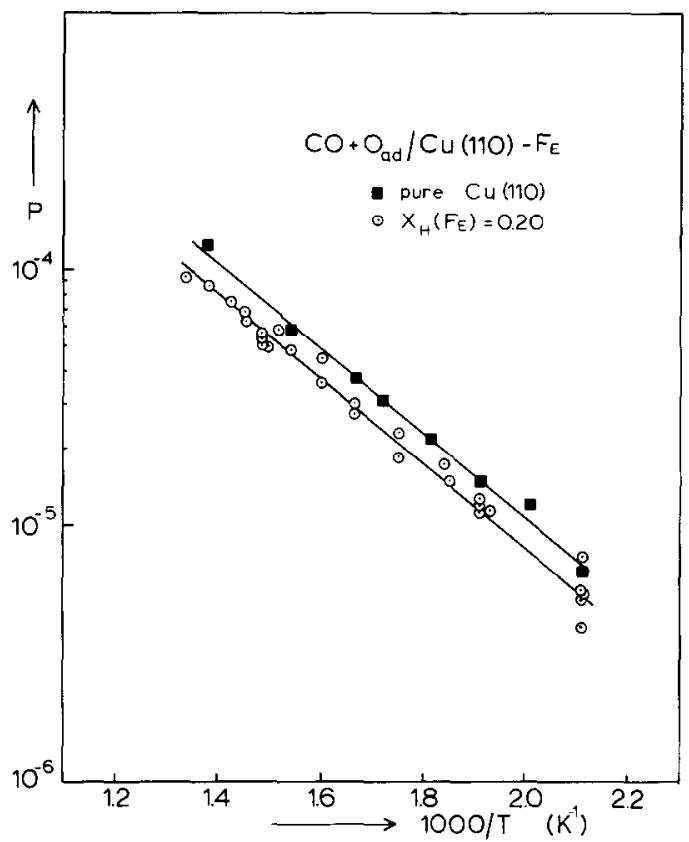

Fig. 2. Arrhenius plot of the reaction probability $P$ of the second stage for the reaction of $\mathrm{CO}$ with adsorbed oxygen.

CO-reduction is performed at higher temperatures the segregation is even more significant. The $h_{\mathrm{O}} / h_{\mathrm{Fe}}$ peak ratio is constant and equal to 3.45 from 300 until $6000 \mathrm{~s}$ sputtering. After high temperature reduction about the same ratios are observed from $600 \mathrm{~s}$ sputtering; until this time the ratio is lower. The areas underneath the sputter profiles were proportional to the values of $\delta \psi_{\mathrm{Fe}}$ after deposition (i.e. the total amount of iron present [6]) within experimental error whether iron was oxidized and reduced or not. Fig. 4a shows the LEED pattern of a surface which has been exposed to $\mathrm{CO}$ until the final slow reduction stage began. After prolonged reduction at high temperatures no pattern was observed at all. Fig. $4 b$ shows the LEED pattern of the clean $\mathrm{Cu}(110)$.

\subsubsection{Repeated admittance of $\mathrm{CO}$}

When $\mathrm{Cu}(110)-\mathrm{Fe}$ was oxidized, again reduced, reoxidized and so on, the kinetics of the CO-reduction and the LEED pattern after the fast stage, changed. After about four cycles all observations reproduced well. Fig. 5 shows $\delta \Delta$ as a function of the CO-exposure at different temperatures for this situation. The similarity with the reduction for pure $\mathrm{Cu}(110)$ is now much 

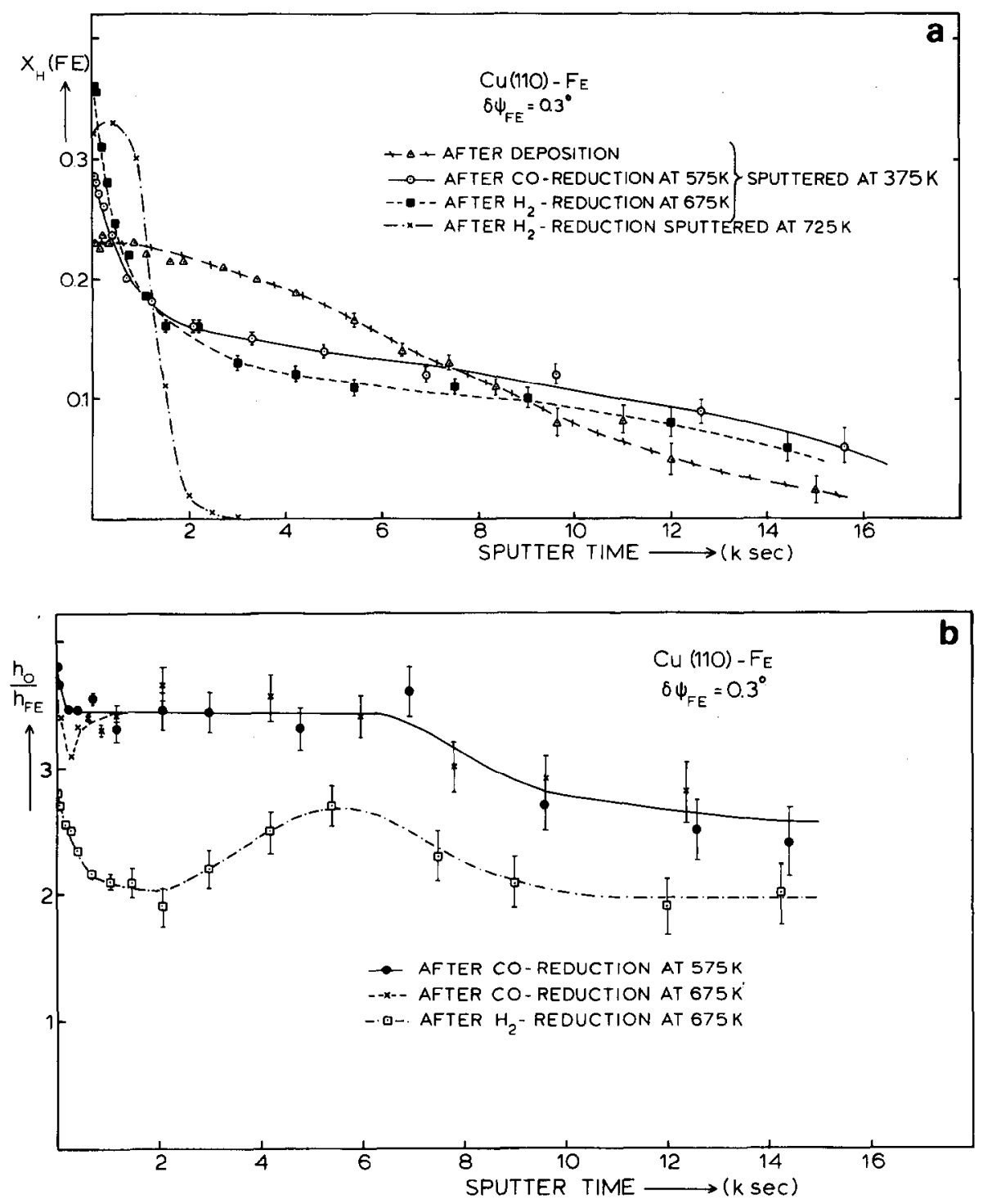

Fig. 3. (a) Iron mole fraction $x_{\mathrm{H}}(\mathrm{Fe})$ and (b) peak ratio $h_{\mathrm{O}} / h_{\mathrm{Fe}}$ as a function of sputter time after reductions interrupted at various stages.

greater since the fast stage lasts about as long. The reaction rates of the fast stage are equal to those observed during the first admittance of $\mathrm{CO}$; again after completed reduction $h_{\mathrm{O}} / h_{\mathrm{Fe}}=3.45 \pm 0.10$, a $47 \mathrm{eV}$ peak and no LEED pattern are observed. Immediately after the fast reduction stage a LEED 


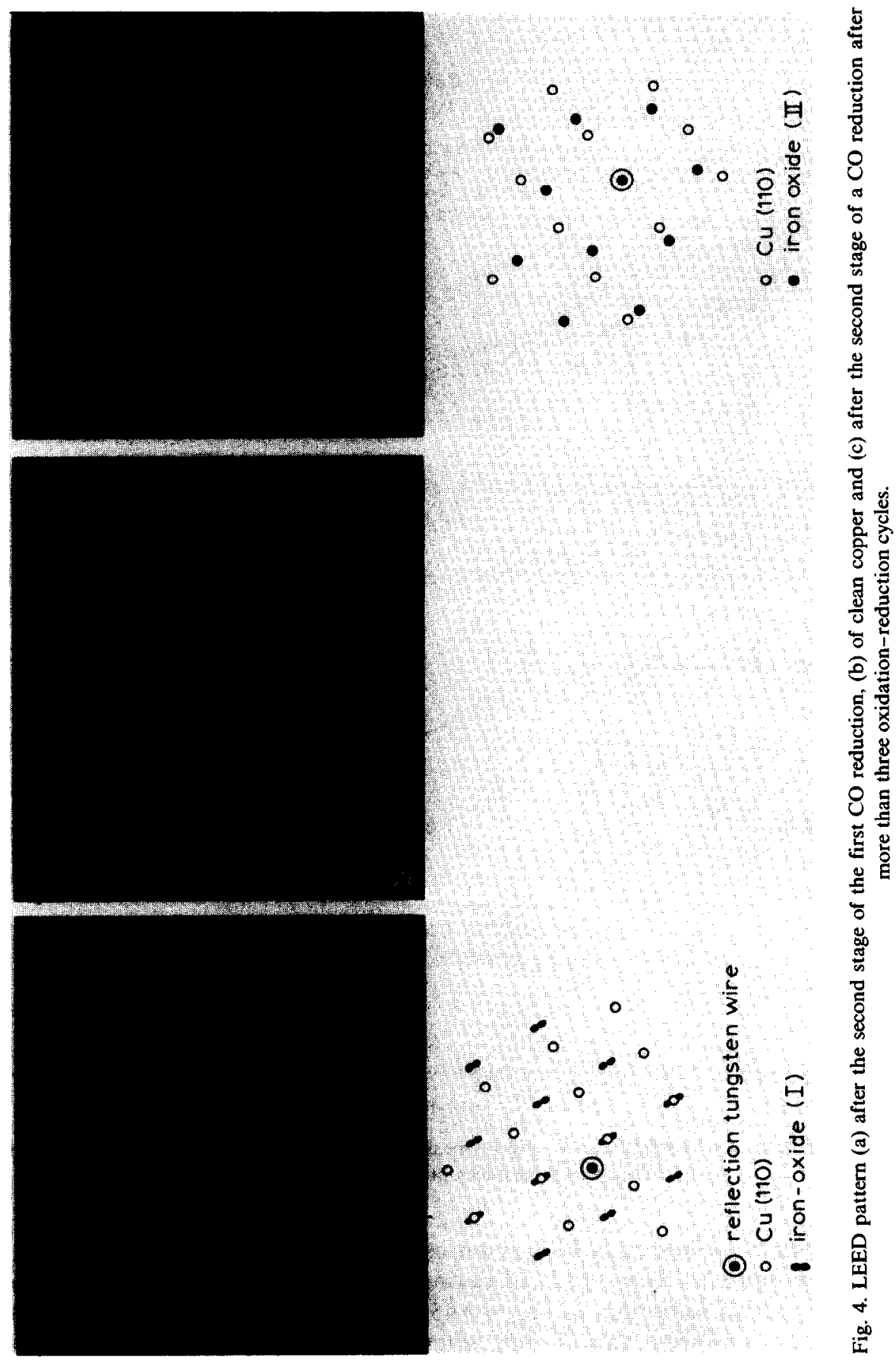




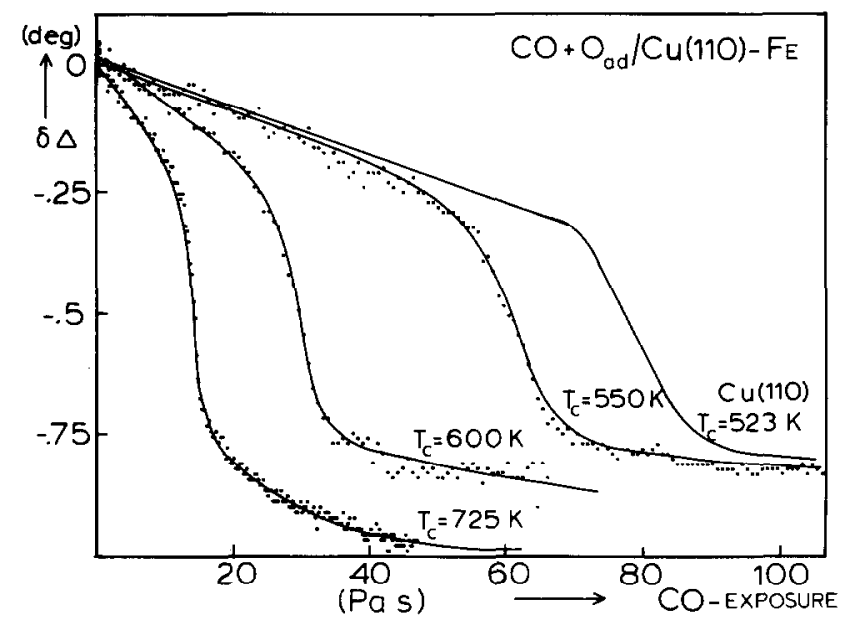

Fig. $5 . \delta \Delta$ versus $C O$-exposure after more than three oxidation-reduction cycles to fully oxidized $\mathrm{Cu}(110)-\mathrm{Fe}$ surface alloys at $x_{\mathrm{H}}(\mathrm{Fe})=0.20$ and different temperatures. Solid lines denote solution of eqs. (1)-(5).

pattern, essentially different from the one observed after the first CO-exposure, is observed which is shown in fig. 4c.

\subsection{Interaction with $\mathrm{H}_{2}$}

The interaction of hydrogen with fully oxidized $\mathrm{Cu}(110)-\mathrm{Fe}$ surface alloys or surfaces prereduced with $\mathrm{CO}$ is studied at pressures from $10^{-2}$ to $1 \mathrm{~Pa}$ and crystal temperatures of 575-725 K. After very large exposures - the reaction with oxygen fades away very slowly - all oxygen can be removed. The reaction showed poor reproducibility; fig. 6 shows the reaction curve that was commonly observed after prereduction by $\mathrm{CO}$. There are three stages discernible. First there is a rather fast reduction until point $D$, then the reaction almost vanishes, but suddenly the rate increases again at point $\mathrm{E}$ (third stage) and then the reaction tails off slowly. (The nomenclature for these stages is taken from ref. [2].) However it appeared that sometimes no slow stage was present and an almost constant reaction rate was measured. Upon exposure of $\mathbf{H}_{2}$ without prereduction with $\mathrm{CO}$ in addition a slow stage was observed first.

As has been pointed out in the former section the kinetics of the CO-reduction changed when multiple reduction cycles were performed. This is also observed for the $\mathrm{H}_{2}$-reduction, but less pronounced. The reaction rate of the first, relative fast stage decreased with the number of $\mathrm{H}_{2}$-exposures as did the total amount of oxygen removed in this stage. To determine the dependence of the rate of this stage on the hydrogen pressure only measurements after about 


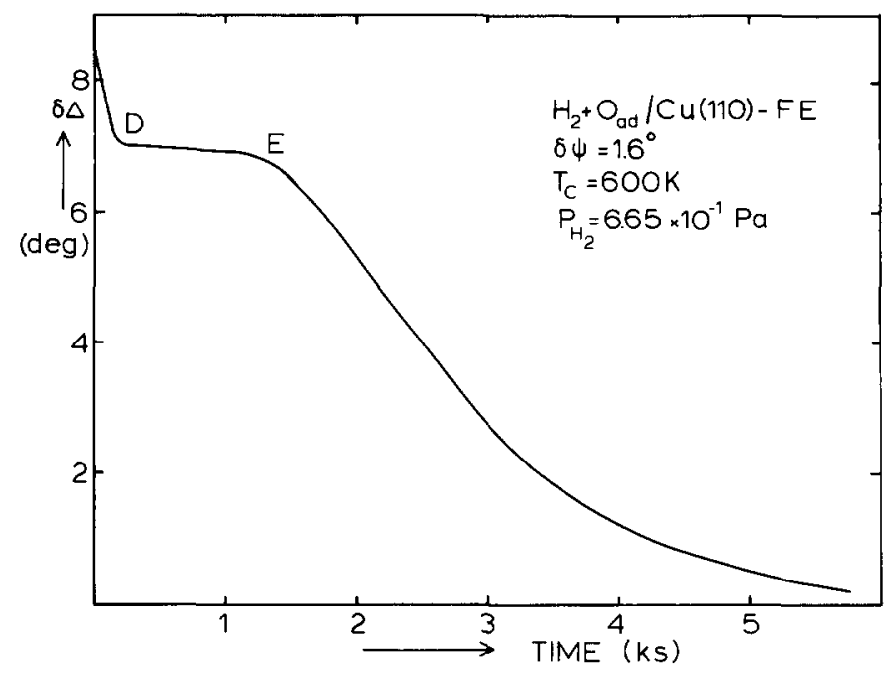

Fig. 6. $\delta \Delta$ versus time during $\mathrm{H}_{2}$-exposure to a $\mathrm{Cu}(110)$-Fe surface at $T_{\mathrm{c}}=600 \mathrm{~K}, p_{\mathrm{H}_{2}}=0.66 \mathrm{~Pa}$ and $\delta \psi_{\mathrm{Fe}}=1.6^{\circ}$.

three cycles could therefore be used. Still no highly reproducible data could be gathered this way at all amounts of iron studied $\left(0.1^{\circ} \leq \delta \psi_{\mathrm{Fe}} \leq 1.6^{\circ}\right)$. The orders found, ranged from 0.3 to 0.8 . The reaction probability $P$ - defined as the number of oxygen atoms removed per incoming hydrogen molecule observed at a pressure of $1.33 \times 10^{-2} \mathrm{~Pa}$ was about $1 \times 10^{-6}$. The AES oxygen to iron peak ratio at point $\mathrm{D}$ is independent of the amount of iron deposited, its value is equal to $h_{\mathrm{O}} / h_{\mathrm{Fe}}=2.8 \pm 0.1$. Iron has segregated to the surface and the iron mole fraction $x_{\mathrm{H}}(\mathrm{Fe})=0.34 \pm 0.02$ is independent of the temperature of reduction. Fig. 3a shows the sputter profile taken at this point at $375 \mathrm{~K}$ and fig. $3 \mathrm{~b}$ shows the peak ratio $h_{\mathrm{O}} / h_{\mathrm{Fe}}$ as a function of sputter time.

The increase of the iron mole fraction at the surface after reduction with $\mathrm{H}_{2}$ is rather surprising. A similar increase of $x_{\mathrm{H}}(\mathrm{Fe})$ was observed when the crystal temperature was increased to $725 \mathrm{~K}$ after an oxidation or a CO-reduction at or below $675 \mathrm{~K}$, suggesting that this segregation was purely thermodynamically induced. To investigate this a crystal was sputtered after $\mathrm{H}_{2}$-reduction until point $\mathrm{D}$ at $725 \mathrm{~K}$ instead of $375 \mathrm{~K}$. As can be seen from fig. 3a no more iron is detected after only $3000 \mathrm{~s}$ of sputtering and it seems as if only a small amount of iron was present initially. Yet an identical amount of iron was deposited as in the crystal sputtered at $375 \mathrm{~K}$.

No segregation was observed when - after an oxidation or CO-reduction at or below $675 \mathrm{~K}$ - the crystal was reoxidized at $725 \mathrm{~K}$ : the iron mole fraction 


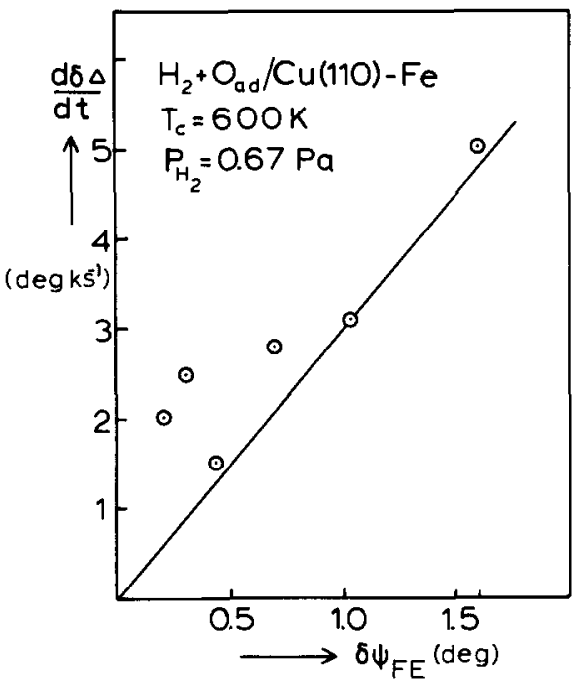

Fig. 7. Reaction rates for the reduction of an oxidized $\mathrm{Cu}(110)-\mathrm{Fe}$ surface during the final $\mathrm{H}_{2}$-reduction stage as a function of the amount of deposited iron. The drawn line is taken from the one found for the same reaction on $\mathrm{Cu}(111)-\mathrm{Fe}$ [2].

observed at the surface decreased from $x_{\mathrm{H}}(\mathrm{Fe})=0.34$ to 0.15 . The composition remained unchanged when the temperature was increased to $775 \mathrm{~K}$.

$\mathrm{On} \mathrm{Cu}(111)-\mathrm{Fe}$ it was observed that when twice as much iron was deposited the reaction rate of the final stage increased proportionally. It is interesting to compare this with the results of the same reaction on $\mathrm{Cu}(110)-\mathrm{Fe}$ (fig. 7). The reaction rate of the final stage increases with the amount of iron deposited identical as on $\mathrm{Cu}(111)-\mathrm{Fe}$.

After complete reduction almost no $h_{47}$ peak was observed and the iron mole fraction had decreased to $x_{\mathrm{H}}(\mathrm{Fe})=0.10$. The LEED pattern showed only the copper pattern, so no facets were present.

\section{Discussion}

\subsection{CO-reduction: general features}

The reduction of oxygen on $\mathrm{Cu}(110)-\mathrm{Fe}$ with $\mathrm{CO}$ shows some similarities with the reduction of pure $\mathrm{Cu}(110)$. Like on $\mathrm{Cu}(110)$ first a slow reduction stage is observed and thereafter a fast stage, of which the rate is almost as fast as that on $\mathrm{Cu}(110)$ (see fig. 5). A difference is that at the moment $\mathrm{Cu}(110)$ is completely reduced, the reduction on $\mathrm{Cu}(110)-\mathrm{Fe}$ continues slowly, though eventually is ceases before all oxygen is removed. After the reduction, no 
LEED pattern is observed, but remarkably one is observed earlier, namely before the final slow reduction stage begins. Surprisingly when more oxidation and CO-reduction cycles are performed, some LEED spots which are observed first, disappear in favour of others. This observation is accompanied by a decrease in the length of the fast reduction stage which is eventually about as long as on $\mathrm{Cu}(110)$. This is the situation shown in fig. 5 .

Whereas some LEED spots disappear and others appear, some remain. It is not difficult, examining figs. $4 \mathrm{a}, 4 \mathrm{~b}$ and $4 \mathrm{c}$, to conclude that those remaining spots originate from clean $\mathrm{Cu}(110)$. This means that, like on $\mathrm{Cu}(111)-\mathrm{Fe}$, copper can be reduced completely. It indicates also that the final slow reduction stage is a reduction of iron.

$\mathrm{On} \mathrm{Cu}(111)-\mathrm{Fe}$ is was shown that the LEED patterns were a superposition of patterns from clean copper and iron oxide. It is logical to assume this also for $\mathrm{Cu}(110)-\mathrm{Fe}$. Both the spots apart from the copper spots observed after the first cycle and those which show up after more cycles form a simple hexagonal pattern. The difference between them is that they are rotated about $35^{\circ}$ with respect to each other. Of course the interatomic distance of the iron oxide at the surface can be derived easily from these patterns. After the first reduction cycles this distance is $2.95 \pm 0.03 \AA$, after repeated cycles it is $3.12 \pm 0.02 \AA$. Both values compare favourably with the fcc $\mathrm{Fe}_{1-x} \mathrm{O}$ wüstite structure which has a hexagonal (111) plane with a spacing of $3.06 \AA$. As the closest packed oxygen atoms in $\mathrm{Fe}_{3} \mathrm{O}_{4}$ have a spacing of $2.97 \AA$ the initially observed oxide corresponds to this iron-oxide structure too.

The change in alignment of the oxide may be explained as follows. The angle of about $35^{\circ}$ by which it rotates is equal to the angle that the diagonal of the rectangular structure of $\mathrm{Cu}(110)$ makes with the long side. This suggests that the rotation is related to the surface structure of copper. The final configuration of the surface is the one that is of course energetically most favourable. The fact that the oxide does not immediately take up this preferred position is easily explained when one considers that before oxidation a facetted iron structure is present, which means that every iron atom has a fixed position with respect to the copper matrix. To remove it from there may not be very easy. So initially when iron is oxidized, the iron oxide must accept a less preferred position. When iron oxide is reduced by $\mathrm{CO}$ and partly by $\mathrm{H}_{2}$, after which the surface is disordered since no LEED pattern is observed, and reoxidized it will be able to take up its most stable configuration. The rotation over $35^{\circ}$ emphasizes the important role that the geometry of the copper surface plays in this change. Since spots is hardly the word to use for the stripe-like appearances of the iron oxide pattern observed after a first reduction, this also shows the bad fit of this structure in the copper matrix (more specifically in the $\langle 011\rangle$ direction).

It is remarkable that the iron oxide fits best when its lattice parameter is precisely half the cross diagonal of the cubic unit cell (6.25 $\AA$ ) of copper and 


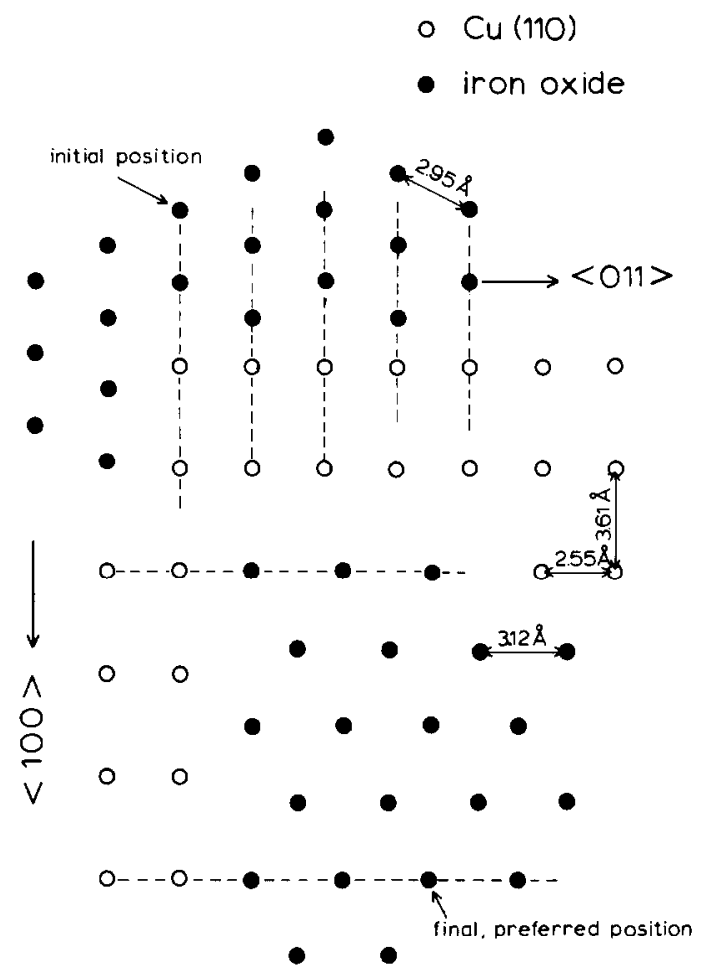

Fig. 8. The position that iron oxide takes up with respect to the $\mathrm{Cu}(110)$ matrix initially and after a few oxidation-reduction cycles (top view). The dotted lines show the alignment with copper.

when there is an alignment in the $\langle 100\rangle$ direction (see fig. 8), whereas the initial position of the iron oxide is less preferred although there is a very good alignment in the $\langle 011\rangle$ direction (fig. 8).

There is a significant difference in the lattice constant of the iron oxide as it is increased from initially 2.95 to $3.12 \AA$. This coincides with the decrease in the length of the fast CO-reduction stage, which means that the amount of oxygen that is incorporated in the iron oxide decreases each cycle. This will be an argument in the discussion for a model of the kinetics later on.

An important question is which iron oxide is observed. On $\mathrm{Cu}(111)-\mathrm{Fe}$ it was determined that a peak ratio $h_{\mathrm{O}} / h_{\mathrm{Fe}}=3.45 \pm 0.10$ and a hexagonal lattice parameter of $3.14 \pm 0.05 \AA$ corresponded to $\mathrm{Fe}_{0.95}$ [2]. As these parameters are observed in the present work after a number of oxidation-reduction cycles the conclusion is that $\mathrm{Fe}_{0.95} \mathrm{O}$, wüstite is observed. As wüstite is observed after only copper has been reduced, it means that even after thorough oxidation only wüstite is formed. This is quite different from $\mathrm{Cu}(111)-\mathrm{Fe}$ where even $\gamma-\mathrm{Fe}_{2} \mathrm{O}_{3}$ was observed. The peak ratios $h_{\mathrm{O}} / h_{\mathrm{Fe}}$ observed during sputtering (fig. 
3b) support the assumptions. There is no contribution of oxygen adsorbed on copper to $h_{\mathrm{O}}$. The constant ratio of $h_{\mathrm{O}} / h_{\mathrm{Fe}}$ of 3.45 during $8000 \mathrm{~s}$ sputtering confirms that throughout a rather deep surface layer a constant stoichiometry $\left(\mathrm{Fe}_{0.95} \mathrm{O}\right)$ exists.

As has already been stated an iron oxide is present after the first $\mathrm{CO}$-reduction, containing more oxygen than $\mathrm{Fe}_{0.95} \mathrm{O}$. On $\mathrm{Cu}(111)-\mathrm{Fe}$ a peak ratio $h_{\mathrm{O}} / h_{\mathrm{Fe}}=4.4 \pm 0.1$ and a hexagonal lattice parameter of $3.01 \pm 0.05 \AA$ corresponded to $\mathrm{Fe}_{3} \mathrm{O}_{4}$. The observed lattice parameter of $2.95 \pm 0.03 \AA$ is in accordance, but the observed peak ratio of $3.9 \pm 0.2$ is not in accordance with an $\mathrm{Fe}_{3} \mathrm{O}_{4}$ species. Therefore we assume that a species like $\mathrm{Fe}_{0.95} \mathrm{O}$ is present with only some extra oxygen at the surface. The importance of the rather small lattice parameter must not be overestimated as the epitaxy of this iron oxide to copper is poor.

An unanswered question is what the continued CO-reduction must be ascribed to. The sputter profile in fig. $3 \mathrm{~b}$ shows that near the outer surface layers oxygen is removed, but after $1000 \mathrm{~s}$ sputtering the peak ratio $h_{\mathrm{O}} / h_{\mathrm{Fe}}$ is again equal to 3.45. As a large amount of iron is near the surface layer (fig. 3a), the amount of removed oxygen is significant and apparently no perfect stoichiometry exists near the surface layer. This is in agreement with the lack of a LEED pattern. So iron is reduced a little and the $\mathrm{Fe}_{0.95} \mathrm{O}$ structure is affected by $\mathrm{CO}$.

Reduction of $\mathrm{Fe}_{0.95} \mathrm{O}$ by $\mathrm{CO}$ was not observed on $\mathrm{Cu}(111)-\mathrm{Fe}$, only $\gamma-\mathrm{Fe}_{2} \mathrm{O}_{3}$ could be reduced to $\mathrm{Fe}_{3} \mathrm{O}_{4}$. So the possibility of reducing $\mathrm{Fe}_{0.95} \mathrm{O}$ is remarkable also in view of the impossibility to reduce oxidized $\mathrm{Fe}(100)$ by $\mathrm{CO}$ [3]. However, the explanation is simple. In the temperature range where our experiments are performed wüstite itself is unstable; it will decompose into $\mathrm{Fe}_{3} \mathrm{O}_{4}$ and $\mathrm{Fe}$ [8]. Apparently wüstite can be stabilized by the hexagonal surface structure of $\mathrm{Cu}(111)$ or $\mathrm{Al}_{2} \mathrm{O}_{3}$ [8]; when no reasonable fit onto the substrate surface is possible the decomposition will (partly) take place. The rectangular shape of $\mathrm{Cu}(110)$ is responsible for this phenomenon.

The study on the reaction rate and its dependence on the temperature was concentrated on the fast reduction stage. The activation energy is equal for $\mathrm{Cu}(110)$ and $\mathrm{Cu}(110)-\mathrm{Fe}$ which was also observed for $\mathrm{Cu}(111)$ and $\mathrm{Cu}(111)-\mathrm{Fe}$. This was explained by assuming that only oxygen atoms on copper sites could react with $\mathrm{CO}$ also adsorbed on copper sites. The decrease in reaction rate with the iron mole fraction was caused by iron oxide which reduced the total copper surface [2]. The activation energies of $\mathrm{Cu}(110)-\mathrm{Fe}$ and $\mathrm{Cu}(111)-\mathrm{Fe}$ are equal within error, $31.5 \pm 0.5$ and $31 \pm 1 \mathrm{~kJ} / \mathrm{mol}$ respectively. This emphasizes the non-plane specific behaviour of this reaction also noticed for pure copper.

\subsection{CO-reduction: model}

The reduction of oxidized $\mathrm{Cu}(110)$ by $\mathrm{CO}$ is well understood [4] in terms of a Langmuir-Hinshelwood mechanism. First there is a slow reaction of surface 
oxygen with adsorbed $\mathrm{CO}$ and a simultaneous migration of subsurface oxygen (unreactive towards $\mathrm{CO}$ ) to a surface site. After completion of this stage the remaining surface oxygen is removed. It was argued in section 4.1 that the final slow reduction was an incomplete reduction of wüstite. To describe the reduction of $\mathrm{Cu}(110)-\mathrm{Fe}$ in addition to the model for $\mathrm{Cu}(110)$ it is assumed that the destabilization of $\mathrm{Fe}_{0.95} \mathrm{O}$ begins at the moment some surface oxygen is removed. Some $\mathrm{Fe}_{0.95} \mathrm{O}$ decomposes into $\mathrm{Fe}_{3} \mathrm{O}_{4}$ and $\mathrm{Fe}$ of which $\mathrm{Fe}_{3} \mathrm{O}_{4}$ is reduced to $\mathrm{Fe}_{0.95} \mathrm{O}$. For clarity the reduction by $\mathrm{CO}$ after a few cycles will be discussed first, and thereafter the reduction immediately after the first oxidation. The reaction scheme is:

$$
\begin{aligned}
& \mathrm{d} \theta_{\mathrm{s}} / \mathrm{d} t=-k_{1} \theta_{\mathrm{s}} \theta_{\mathrm{CO}}+k_{2} \theta_{\mathrm{sub}}\left(\theta_{\mathrm{s}}^{\mathrm{O}}-\theta_{\mathrm{s}}\right)+k_{3} \theta_{\mathrm{FeO}}\left(\theta_{\mathrm{s}}^{\mathrm{O}}-\theta_{\mathrm{s}}\right), \\
& \mathrm{d} \theta_{\mathrm{sub}} / \mathrm{d} t=-k_{2} \theta_{\mathrm{sub}}\left(\theta_{\mathrm{s}}^{\mathrm{O}}-\theta_{\mathrm{s}}\right), \\
& \mathrm{d} \theta_{\mathrm{FeO}} / \mathrm{d} t=-k_{3} \theta_{\mathrm{FeO}}\left(\theta_{\mathrm{s}}^{\mathrm{O}}-\theta_{\mathrm{s}}\right), \\
& \theta_{\mathrm{CO}}=K\left(\theta_{\mathrm{s}}^{\max }-\theta_{\mathrm{s}}\right) P_{\mathrm{CO}}, \\
& \theta_{\mathrm{s}}^{\max }=0.5\left(1-\alpha x_{\mathrm{H}}(\mathrm{Fe})\right),
\end{aligned}
$$

where $\theta_{\mathrm{s}}, \theta_{\text {sub }}$ and $\theta_{\mathrm{FeO}}$ are the surface, subsurface and reacting FeO oxygen coverages, $\theta_{\mathrm{s}}^{\max }$ the maximum fraction of surface sites where $\mathrm{CO}$ may adsorb, $\theta_{\mathrm{s}}{ }^{\mathrm{O}}$ the maximum fraction of surface sites occupied by oxygen, $\alpha x_{\mathrm{H}}(\mathrm{Fe})$ is the number of sites blocked by iron-oxide crystallites and the $k$ 's are rate constants. For the numerical fit the values for $k_{1}, k_{2}, K$ and $\theta_{\mathrm{s}}^{\mathrm{O}}$ of pure $\mathrm{Cu}(110)$ were used [4]. Fig. 5 shows the results of simulations of the reduction at three temperatures. To be able to fit we had to take a value for $\alpha=0.7 \pm 0.1$, whereas on $\mathrm{Cu}(111)-\mathrm{Fe} \alpha=1.4 \pm 0.1$ was found. The difference is simply due to the difference in the number of sites $N$ on $\mathrm{Cu}(110)$ and on $\mathrm{Cu}(111)$. Assuming that an iron atom on $\mathrm{Cu}(110)-\mathrm{Fe}$ possesses the same unit area as on $\mathrm{Cu}(111)-\mathrm{Fe} \alpha=0.85 \pm 0.10$ should be expected on $\mathrm{Cu}(110)-\mathrm{Fe}$ since the ratio of sites is $N(110) / N(111)=0.61$. The agreement between the expected and experimental value for $\alpha$ is satisfactory.

The reaction rate in the fast stage (when $\theta_{\text {sub }} \simeq 0$ since all subsurface oxygen is converted to surface oxygen and $\left.k_{3} \theta_{\mathrm{Fe}}<k_{1} K P_{\mathrm{Co}} \theta_{\mathrm{s}}\right)$ is:

$r=-k_{1} K \theta_{\mathrm{s}}\left(\theta_{\mathrm{s}}^{\max }-\theta_{\mathrm{s}}\right) P_{\mathrm{CO}}$

The activation energy is determined by $k_{1}$ and $K$ like on $\mathrm{Cu}(110)$, thus the fact that the activation energies on $\mathrm{Cu}(110)$ and $\mathrm{Cu}(110)-\mathrm{Fe}$ are equal is in agreement with the model.

To explain the reaction curves observed during the first $\mathrm{CO}$-exposure it is assumed that some extra oxygen $\mathrm{O}+$ is bound to iron which can easily be 
removed once the surface oxygen coverage decreases. So instead of eq. (1) we have:

$\mathrm{d} \theta_{\mathrm{s}} / \mathrm{d} t=-k_{1} \theta_{\mathrm{s}} \theta_{\mathrm{CO}}+k_{2} \theta_{\mathrm{sub}}\left(\theta_{\mathrm{s}}^{\mathrm{O}}-\theta_{\mathrm{s}}\right)+k_{2} \theta_{\mathrm{FeO}}\left(\theta_{\mathrm{s}}^{\mathrm{O}}-\theta_{\mathrm{s}}\right)+k_{4} \theta_{\mathrm{O}+}\left(\theta_{\mathrm{s}}^{\mathrm{O}}-\theta_{\mathrm{s}}\right)$,

$\mathrm{d} \theta_{\mathrm{O}+} / \mathrm{d} t=-k_{4} \theta_{\mathrm{O}+}\left(\theta_{\mathrm{s}}^{\mathrm{O}}-\theta_{\mathrm{s}}\right)$.

The results of the simulation using eqs. (2)-(5), (7) and (8) is shown in fig. 1. As can be seen the model is able to fit the reaction curves. Fitting was possible with $k_{1} K P_{\mathrm{CO}} \theta_{\mathrm{s}} / 2 \theta_{\mathrm{O}+}<k_{4}<2 k_{1} K P_{\mathrm{CO}} \theta_{\mathrm{s}} / \theta_{\mathrm{O}_{+}}$, so no exact values for $k_{4}$ could be determined. For $\theta_{\mathrm{O}+}$ and $\theta_{\mathrm{FeO}}$ respectively 0.8 and 0.4 was obtained. The activation energy of $k_{3}$ was about $80 \mathrm{~kJ} / \mathrm{mol}$.

\section{3. $\mathrm{H}_{2}$-reduction}

In section 4.1 it was stated that after a pre-exposure of $\mathrm{CO}$ the reduction with hydrogen will start at a stage when already some wüstite has decomposed. First $\mathrm{H}_{2}$-reduction occurs relatively fast (up to point $\mathrm{D}$ in fig. 6), but then the reaction rate drops quickly. $\mathrm{On} \mathrm{Cu}(111)-\mathrm{Fe}$ the same behaviour was noticed and it was ascribed to the beginning of the reduction of wüstite. This cannot be the case on $\mathrm{Cu}(110)-\mathrm{Fe}$; the nomenclature in fig. 6 therefore merely corresponds to the one of $\mathrm{Cu}(111)-\mathrm{Fe}$ in the sense that it points to identical changes in reactivity.

At point $D$ no stoichiometric iron-oxide can be present of course since wüstite is the species with the lowest oxidation state of iron. Two observations support this. The first is that there is no LEED pattern observed at point $D$. Secondly the peak ratio $h_{\mathrm{O}} / h_{\mathrm{Fe}}$ during sputtering (fig. $3 \mathrm{~b}$ ) is not constant and excludes stoichiometry throughout the crystal. The value of $h_{\mathrm{O}} / h_{\mathrm{Fe}}=2.8$ at the surface is in accordance with the assumption that wüstite has been reduced, since $h_{\mathrm{O}} / h_{\mathrm{Fe}}=3.45$ corresponds to wüstite.

As for $\mathrm{Cu}(111)-\mathrm{Fe}$ sudden changes in reaction rate during reduction were ascribed to transitions of iron-oxide species, one wonders what causes the decrease at point $D$. Two extra experiments were performed to understand this. But first we recall the following results.

The variation of $h_{\mathrm{O}} / h_{\mathrm{Fe}}$ during sputtering of a crystal at point $\mathrm{D}$ is remarkable (see fig. 3b). The maximum of $h_{\mathrm{O}} / h_{\mathrm{Fe}}$ after $6000 \mathrm{~s}$ sputtering suggests that oxygen bound to iron at a corresponding deep layer will hardly diffuse to the surface to be removed. In ref. [6] it was proved that during oxidation of $\mathrm{Cu}(111)-\mathrm{Fe}$ not oxygen but merely iron and iron-oxide atoms are mobile. Therefore it is assumed that to become reduced iron oxide atoms must diffuse to the surface. This implies that during reduction much iron must be present at the surface as iron oxide. As at point $D$ and after complete CO-reduction segregation of iron is observed (fig. 3a) this assumption is 
strongly supported. Since this segregation is apparently limited to $x_{\mathrm{H}}(\mathrm{Fe})=$ 0.34 (see fig. 3a) this may limit the reduction process and another diffusion mechanism must take over the oxygen transport to continue the reduction.

Apparently diffusion to the surface is slow at point $D$. This should also be noticed when the crystal is oxidized at point $D$. To investigate this an oxidation was performed at $675 \mathrm{~K}$ after $\mathrm{H}_{2}$-reduction until point $\mathrm{D}$, until saturation occurred, i.e. the sticking coefficient became lower than $1 \times 10^{-4}$. Next the vacuum chamber was evacuated and the crystal was kept at $475 \mathrm{~K}$ for two hours. Then oxygen was re-exposed and now an initial sticking coefficient of about $1 \times 10^{-1}$ was observed and an amount of oxygen corresponding to half a monolayer could easily be adsorbed! Thus a slow (most probably unactivated) diffusion process had made copper sites free to readsorb. To verify this the experiment was repeated but after oxidation at $675 \mathrm{~K}$ the crystal was cooled to $300 \mathrm{~K}$. LEED patterns after all standard oxidation

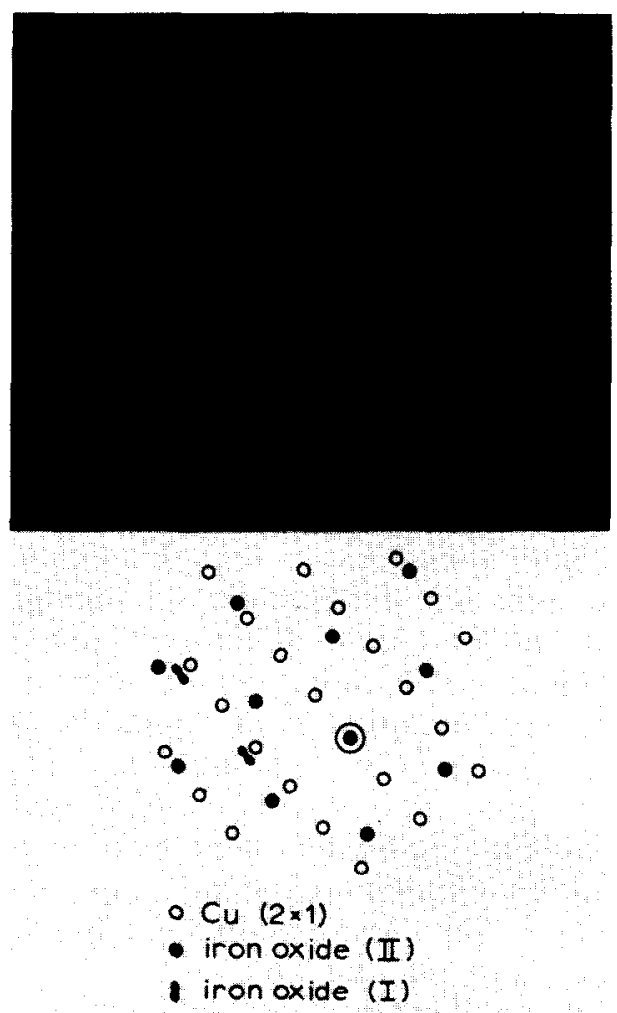

Fig. 9. LEED pattern after oxidation at $675 \mathrm{~K}$ immediately after $\mathrm{H}_{2}$-reduction until point $\mathrm{D}$, showing a superposition of $\mathrm{Fe}_{0.95} \mathrm{O}$ and $\mathrm{a}(2 \times 1)$ structure of $\mathrm{O}_{\mathrm{ad}} / \mathrm{Cu}(110)$. 
experiments at $675 \mathrm{~K}$ had revealed a $\mathrm{c}(6 \times 2)$ structure [6], but instead of this a superposition of a copper $(2 \times 1)$ structure and a wüstite structure (fig. 9) was observed. Since a $(2 \times 1)$ structure corresponds to a less far oxidized state of copper, oxygen must have been transported to iron, which was oxidized at the expense of copper. During the relatively short oxygen exposure oxygen cannot penetrate fast enough to iron in deeper layers and therefore the oxidation will stop. This same slow oxygen transport will then limit the reduction rate at point D.

Accurate determinations of the order of the reaction on the hydrogen pressure were difficult due to the decrease of the reaction rate with the number of cycles and the overall irreproducibility. An order of a 0.5 seems most probable from the experimental values. The same order was found for $\mathrm{Cu}(111)-\mathrm{Fe}$ and it implies that iron facilitates hydrogen dissociation $[2,4]$.

The sputtering of an alloy at $725 \mathrm{~K}$ incompletely reduced with $\mathrm{H}_{2}$ (see fig. $3 a)$ has an obvious explanation. When it would have been sputtered at $375 \mathrm{~K}$ iron would be removed after more than $20000 \mathrm{~s}$ (see fig. 3a). At $725 \mathrm{~K}$ all iron has disappeared after $3000 \mathrm{~s}$. It can only be explained when iron oxide segregates during sputtering.

Since after reoxidation at $725 \mathrm{~K}$ no segregation is observed, wüstite itself does not segregate, it does only when it is oxygen deficient.

The final stage of hydrogen reduction is not thoroughly investigated because of the large exposures necessary. Although the scatter of the reaction rates is large, the dependence of them on the amount of iron deposited is the same as on $\mathrm{Cu}(111)-\mathrm{Fe}$ [2].

\section{Conclusion}

Copper in a thoroughly oxidized $\mathrm{Cu}(110)-\mathrm{Fe}$ crystal can be reduced completely by $\mathrm{CO}$. Since a small part of $\mathrm{Fe}_{0.95} \mathrm{O}$, which is the only iron oxide that can be formed even after severe oxidation, decomposes into $\mathrm{Fe}_{3} \mathrm{O}_{4}$ and $\mathrm{Fe}$, also some iron can be reduced. Initially $\mathrm{Fe}_{0.95} \mathrm{O}$ takes up a different orientation with respect to the copper matrix than after a few cycles of (incomplete) reduction and oxidation. The less preferred orientation is induced by the presence of iron facets before the oxidation. The reaction with $\mathrm{CO}$ can be simulated with a model which is an extension of the model for the same reaction on pure $\mathrm{Cu}(110)$. The reaction takes place on copper sites and the influence of iron oxide is mainly to reduce the copper surface; this reduction factor is the same as on $\mathrm{Cu}(111)-\mathrm{Fe}$ when the density of copper atoms on both copper surfaces is taken into account.

With hydrogen all oxygen can be removed from a $\mathrm{Cu}(110)-\mathrm{Fe}$ crystal. The reaction rate which is first relatively fast decreases due to a slow transport of oxygen to the surface, but thereafter it increases again. When $\mathrm{Fe}_{0.95}$ is oxygen 
deficient - due to CO-reduction, a partial $\mathrm{H}_{2}$-reduction or incomplete oxidation - it segregates at $725 \mathrm{~K}$. This becomes more evident when it is sputtered at $725 \mathrm{~K}$ since then it is removed much faster than at $375 \mathrm{~K}$.

\section{Acknowledgement}

We would like to thank Kees van Leerdam for his part in the experimental work.

\section{References}

[1] O.P. van Pruissen, E. Boellaard, O.L.J. Gijzeman and J.W. Geus, Appl. Surface Sci. 27 (1986) 1.

[2] O.P. van Pruissen, M.M.M. Dings, E. Boellaard, O.L.J. Gijzeman and J.W. Geus, Appl. Surface Sci. 27 (1986) 24.

[3] T.J. Vink, J.M. der Kinderen, O.L.J. Gijzeman and J.W. Geus, Appl. Surface Sci. 26 (1986) 367.

[4] O.P. van Pruissen, M.M.M. Dings and O.L.J. Gijzeman, Surface Sci. 179 (1987) 377.

[5] F.C. Schouten, E.W. Kaleveld and G.A. Bootsma, Surface Sci. 63 (1977) 460.

[6] O.P. van Pruissen, G.C. van Leerdam, O.L.J. Gijzeman and J.W. Geus, Appl. Surface Sci. 29 (1987) 86.

[7] F.H.P.M. Habraken and G.A. Bootsma, Surface Sci. 87 (1979) 333.

[8] A.F.H. Wielers, A.J.H.M. Kock, C.E.C.A. Hop, J.W. Geus and A.M. van der Kraan, J. Catalysis, submitted. 